Faculdade de Ciências Econômicas UFRGS
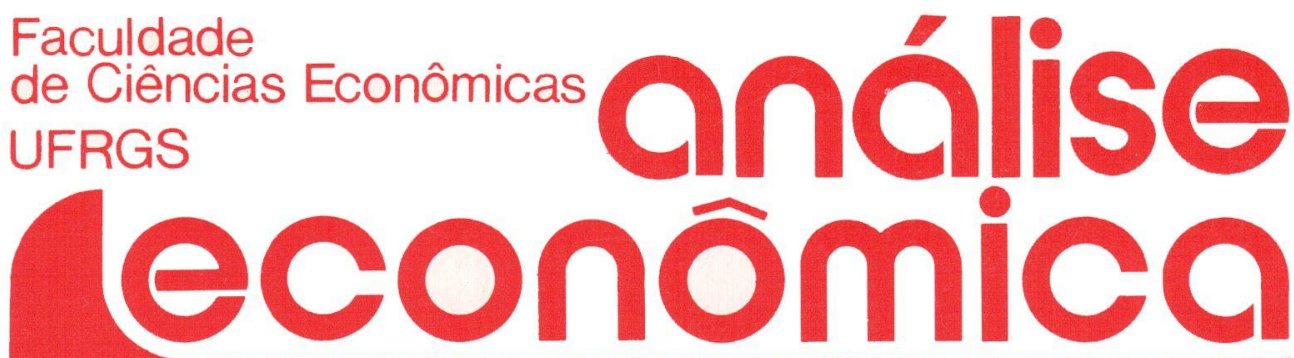

- A LINEAR MOdEL Of BALANCEd GROWTH Joanilio Rodolpho Teixeira Rodrigo Andrés de Souza Penaloza

- TEORIAS ESTRUTURALISTAS DA INFLAÇÃO

Roberto Camps Moraes

- PREÇOS EXTERNOS E EXPÓRTAÇÃO DE MANUFATURADOS Lauro Lobo Burle

- O DESENVOLVIMENTO SUECO Alfredo Marcolin Peringer

- DÉFICIT ENERGÉTICO Fabiano Augusto Nogueira Pinto

- RICARDO E O PROBLEMA SOCIAL Cezar Machado Mello

- UM SABER QUE NÃo SABE: INSTRUMENTO DE PREVISÃO Eleutério F.S. Prado

- SELEÇÃo dE PLANOS DE PRODUÇÃO PARA PEQUENOS PRODUTORES AGRICOLAS Juvir Luiz Mattuella

- PERSPECTIVAS da ECONOMIA do NORDESTE NA DÉCADA DE NOVENTA

Liana Maria da Frota Carleial

- CAIO PRADO JÚNIOR

Pedro Cezar Dutra Fonseca 
UNIVERSIDADE FEDERAL DO RIO GRANDE DO SUL Reitor. Prof. Tuiskon Dick

FACULDADE DE CIÊNCIAS ECONÔMICAS

Diretor: Prof. Walter Meucci Nique

CENTRO DE ESTUDOS E PESQUISAS ECONÔMICAS

Diretor: Reinaldo lgnácio Adams

DEPARTAMENTO DE CIÉNCIAS ECONÔMICAS

Chefe: Prof. Pedro Cezar Dutra Fonseca

CURSO DE PÓS-GRADUAÇÃO EM ECONOMIA

Coordenador: Prof. Nali de Jesus de Souza

CURSO DE PÓS-GRADUAÇĀO EM ECONOMIA RURAL

Coordenador. Prof. Atos Freitas Grawunder

CONSELHO EDITORIAL: Achyles Barcelos da Costa, Aray Miguel Feldens, Atos Freitas Grawunder, Carlos Augusto Crusius, Ernani Hickmann, João Rogério Sanson, Juvir Luiz Mattuella, Maria Imilda da Costa e Silva, Nali de Jesus de Souza, Nuno Renan Lopes de Figueiredo Pinto, Otília Beatriz Kroeff Carrion, Otto Guilherme Konzen, Paulo Alexandre Spohr, Pedro Cezar Dutra Fonseca, Reinaldo Ignacio Adams, Roberto Camps Moraes, Valter José Stülp, Yeda Rorato Crusius, David Garlow (Wharton Econometrics Forecasts Association, E.U.A.), Edgar Augusto Lanzer (UFSC), Eleutério F.S. Prado (USP), Fernando Holanda Barbosa (FGV/RJ), Gustavo Franco (PUC/RJ), Joaquim Pinto de Andrade (UnB), Juan H. Moldau (USP), Werner Baer (Univ. de Illinois, E.U.A.).

COMISSĀO EDITORIAL: Atos Freitas Grawunder, Pedro Cezar Dutra Fonseca, Reinaldo Ignacio Adams e Roberto Camps Moraes.

EDITOR: Nali de Jesus de Souza

SECRETARIA: Maria Ivone de Mello (normalização), Vanete Ricacheski (revisão de textos), Zélide Bregalda (Secretária).

FUNDADOR: Prof. Antônio Carlos Santos Rosa

Os materiais publicados na revista Análise Econômica são de exclusiva responsabilidade dos autores. É permitida a reprodução total ou parcial dos trabalhos, desde que seja citada a fonte.

Aceita-se permuta com revistas congêneres. Aceitam-se, também, livros para divulgação, elaboração de resenhas ou recensōes.

Toda correspondência, material para publicação, assinaturas e permutas devem ser dirigidos ao seguinte destinatário:

PROF. NALI DE JESUS DE SOUZA

Revista Análise Econômica

Av. João Pessoa, 52

90.040 - PORTO ALEGRE (RS), BRASIL

Telefone: (0512) 25-58-44 ramal 33

Fax: (0512) 25-5253 


\title{
UM SABER QUE NÃO SABE: INSTRUMENTO DE PREVISÃO
}

Eleutério F.S. Prado ${ }^{1}$

\begin{abstract}
SINOPSE
Faz-se no artigo um reexame da bem conhecida e controvertida proposta metodológica de Friedman. Procura-se mostrar, por meio de uma crtica interna, que o texto se encontra eivado de contradiçőes. Sugere-se, ainda, que a proposta foi construlda a partir de uma estratégia de argumentação orientada pelo propósito de proteger a teoria neoclássica de crticas. O artigo procura tornar evidente ainda que Friedman, nesse intento, viola a ética implicita do discurso acadêmico que tem como pressupostos internos a busca da verdade, a correção normativa e a sinceridade.
\end{abstract}

\section{PARA QUE TEORİA?}

Friedman, no ensaio A Metodologia da Economia Positiva (1953), busca enfrentar um problema que se lhe afigura, na época em que o escreve, como importante: certas teorias econômicas que lhe parecem boas, justamente as mais bem-sucedidas, estão sendo ameaçadas por críticos que um comentador do texto considerou subversivas (Melítz 1965, p.37). Eles parecem atingir o núcleo mais racional da teoria econômica, fazendo muito barulho. Frente à situação, o seu propósito é fornecer firmes critérios que balizem as controvérsias econômicas, escoimando-as tanto quanto possivel de certo tipo de crítica que considera perigosa.

1 Professor do Curso de Pós-Graduação em Economia da FIPE/USP e do Departamento de Economia da FEA/USP. O presente texto é um capftulo da tese de livre-docéncia do autor (Prado, 1989).

\begin{tabular}{|l|l|l|l|l|}
\hline ANÅLISE ECONO̊MICA & ANO 8 & NN 14 & NOVEMBRO/90 & p.105-121 \\
\hline
\end{tabular}


Antes de mais nada, é preciso ver que a Economia, para ele, em definitivo, é uma ciência positiva. Tal como para Neville Keynes que cita - e em cuja autoridade se apoia -, ela, assim concebida, constitui-se de "um corpo de conhecimentos sistematizados a respeito do que é" (1953, p.3). Sobre isso não deveria haver engano ou confusão. A ęconomia positiva não discute nem os critérios decisórios nem propõe preceitos sobre o que deve ser. Parece-lhe, portanto, do mesmo modo que para o outro, que é "ao mesmo tempo possível e desejável investigar as uniformidades econômicas independentemente dos ideais econômicos" (Keynes 1917, p.36). Desejável, em suma, porque almeja para aquilo que vê como conhecimento positivo o atributo da neutralidade diante dos interesses e dos fins individuais ou coletivos. Possivel, antes de mais nada, porque admite que os fenômenos sociais apresentam regularidades e que estas podem ser apreendidas por meio da observação. Friedmam crê, assim, na possibilidade de conhecê-los com a mesma objetividade com que se fixa na forma lógica dedutiva os fenômenos naturais. ${ }^{2}$

A distinção e separação, na esfera do saber, do que concerne estritamente ao objeto, exige uma garantia forte. Exige, sobretudo, a suposição de que o sistema de conhecimentos de que fala Friedman, com as palavras de Keynes, é, ou pode vir a ser, uma coleção de verdades objetivas ou, menos do que isso, pode pelo menos, de algum modo, disto ir se aproximando. Se é assim, parece justo indagar - o que fica aqui para posterior resposta - se, para o autor de A Metodologia da Economia Positiva, a ciência econômica já é ou pode chegar a ter tal atributo e de que modo.

Para Friedman, como deixa claro nesse texto, a Economia Positiva não é e não deve ser um saber inconseqüente; ao contrário, só vale e somente pode valer por suas implicações para as formulações prescritivas, ou seja, pelo que pode fornecer de certo e de seguro para a política econômica. As suas conclusōes são e devem ser imediatamente relevantes para a solução dos problemas que aparecem quando determinado objetivo precisa ser alcançado. Se, em si mesma, não diz em geral o que desejar - ele parece considerar que contribui em muito para defi$\mathrm{ni}-\mathrm{O}^{3}$ - deve saber dizer como fazer para atingir os fins socialmente co-

2 "Em poucas palavras" - afirma Friedman -, "a economia positiva é, ou pode ser, uma ciência "objetiva", precisamente no mesmo sentido de qualquer ciência ffsica" (1953, p.4).

3 Diz Friedman: "As conclusōes da economia positiva parecem ser, e são, imediatamente relevantes para os problemas normativos importantes, para as questōes do que deveria ser feito e de como um dado objetivo pode ser atingido" (1953, p.4). 
limados. Por isso, "sua tarefa consiste em fornecer um sistema de generalizações que possa ser utilizado para fazer predições corretas sobre as conseqüências de qualquer mudança das circunstâncias" (1953, p.4). Por isso, também, "o seu desempenho deve ser julgado pela precisão, alcance e conformidade com a experiência das predições que fornece" (1953, p.4).

$\mathrm{O}$ autor acredita que as proposições imperativas a respeito do futuro da sociedade baseiam-se sempre em previsões positivas, ainda que nem sempre científicas, sobre o curso possivel dos acontecimentos. Quando se propõe que algo deva ser, necessariamente ou se aceita ou se rejeita o que se pensa que será. Nisto encontra, aliás, a importância do conhecimento cientifico; este parece fornecer, e fornece, instrumentos adequados e precisos para prognosticar o que vai ou pode acontecer, tornando possivel, assim, decisões que levem a uma manipulação mais eficiente da realidade.

Friedmam convém, por um lado, que o acordo sobre as conseqüências de determinado ato legislativo - por exemplo, que a fixação de um salário mínimo acima do salário de mercado reduzirá, provavelmente, a demanda de trabalho - não implica concordância sobre se tal ato deve ou não ser efetuado. Sustenta, por outro, que as diferenças acerca de política econômica, entre cidadãos desinteressados e razoáveis (norte-americanos, certamente), advêm ante e quase sempre de diferenças quanto às previsões sobre os resultados da implementação de determinada política, do que, propriamente, de divergências quanto aos objetivos a serem perseguidos. $E$, assim, descobre urna razão importante para manter a distinção entre o positivo e o normativo em Economia: "a contribuição que [o desenvolvimento do conhecimento] pode dar à conquista de acordo em política econômica" (1953, p.4-5). ${ }^{4}$

$O$ patente objetivismo em que se assenta essas posições - devese notar - cumpre aqui um papel, de um modo claro: o conhecimento não parece depender de um acordo racionalmente motivado, mas, ao contrário, funda a possibilidade de um consenso. Permite, assim, postular a solução de problemas políticos-práticos de um modo técnicocientífico.

Friedman coleta elementos heterogêneos para construir a sua

4 O economista liberal aspira aqui por uma certa unidade de opinião na sociedade. Já Comte, o sociólogo da ordern e do progresso, apreciara o valor da ciéncia positiva para a obtenção de consenso social (1983a, p.17-18). E este autor era, como se sabe, um inimigo do liberalismo. 
concepção do método apropriado à Economia. ${ }^{5}$ A leitura de seu polêmico ensaio metodológico, mostra que duas preocupações centrais levaram-no a escrevê-lo. Uma delas vem a se justificar as suas prescrições de política macroeconómica, baseadas em sua versão da teoria quantitativa da moeda. Mesmo uma evidência "direta, dramática e convincente", como a de que às elevações céleres da quantidade de moeda seguem-se aumentos velozes dos preços, sempre encontrará - lamenta alguma resistência à aceitação entre os especialistas (1953, p.11).

A outra concerne ao seu intento de dar suporte à teoria neoclássica da concorrência perfeita frente às da concorrência imperfeita e monopolística. A primeira, apesar de sua simplicidade e de sua eficácia preditiva, fora muitas vezes atacada na história da ciência, com a acusação de que os seus supostos estão desprovidos de realismo. Essas teorias heterodoxas - assevera - desenvolveram-se sob a motivação explícita de que os supostos da competição perfeita subjacentes à teoria neoclássica básica são falsas imagens da realidade (1953, p.15). Ora, essa atitude crítica e essa ambição de veracidade direcionara mal os esforços científicos e contribuira para que o desacordo se instalasse na teoria econômica. Também a hipótese de maximização de lucros, tão fértil em Economia - pensa -, parecera a muitos não ser consistente com as observações factuais obtidas por meio de questionários em que se indagava pelos motivos que haviam guiado os empresários na tomada de decisões. Para ele, nunca convém questionar hipóteses desse modo. Pois importa tão somente perguntar, em geral, se a partir delas obtêm-se resultados com adequada capacidade de previsão.

Em resumo, Friedman procura encerrar a ortodoxia neoclássica e monetarista dentro de uma concepção de ciência em que as teorias se orientam, em exclusivo, para servir à política econômica. As formulações científicas são concebidas, assim, estritamente como instrumentos para a ordenação da sociedade. Isentos, no entanto!

Ele se apóia em Neville Keynes para postular a distinção normativa positiva; para esse autor, porém, os princípios da ciência econômica são verdadeiros a priori. Essa posição metodológica, no entanto, é por

5 Stanley diz corajosamente o óbvio quando afirma que o texto de Friedman "não é claro, coerente e sem ambigüidades e que pode ser interpretado 'as you like it' "'(1985, p.305). E mostra que já fora lido como expressão de convencionalismo, instrumentalismo, falseacionismo e verificacionismo. Recentemente, McCloskey, na perspectiva do contextualismo radical e antipositivista de Rorty, considerou-o como uma brilhante peça de retórica económica (1985, p.910). Ora, para Friedman, a teoria econômica vale pelo seu poder de predição; para Mccicloskey, as prediçбés são impossiveis em Economia! 
ele rejeitada e isto será melhor esclarecido depois. O seu caminho é outro. Para explicar o que é teoria e qual o seu papel na ordem do pensamento, ampara-se em certas idéias presentes no positivismo lógico. Ao tratar da questão da justificação do conhecimento, colhe argumentos no confirmacionismo, a posição metodológica daqueles positivistas que, havendo se convencido da impossibilidade de se certificar da verdade no âmbito da ciência empírica, consolam-se com a possibilidade de ir acumulando para as teorias evidências que as confirmem. ${ }^{6}$

\section{VALIDADE DA TEORIA}

Friedmam vê teoria, primeiro, como "linguagem". Teoria é, assim, um sistema de termos e proposições que se constitui em instrumento de raciocínio sistemático. Desse ângulo considerada, "carece de conteúdo substantivo"; nada mais é do que "um conjunto de tautologias" (1953, p.7). Dessa perspectiva formal, consiste meramente de um arquivo (filing system) em que se organiza, guarda e acumula o material coIhido pela observação dos fatos. Vem a ser, dizendo de outro modo,

6 No positivismo lógico, sustenta-se sempre que as proposiçóes (não analfiticas) são cientfficas se e somente se tếm significánčia cognitiva. Como é corrente de pensamento pertencente à tradiçắo empirista, requer que se admita que o conhecimento se origina na experiência e se circunscreve à apreensão do que é imediatamente dado. No que aqui interessa, isto implica assentar o critério de valor cognilivo e de valor cientffico na evidéncia emplrica. Assim, para essa posição metodológica, ern geral, uma proposiçăo vem a ser cientffica se for julgável quanto à veracidade no confronto com os fatos. Os autores do Cfrculo de Viena, inicialmente, tenderam a admitir como critério de significáncia cognitiva dos enunciados a circunståncia de que fossem verificáveis, isto $\hat{e}$, aceitáveis como verdadeiros definitiva e completamente. Nesse caso - é preciso aqui enfatizar -, acredita-se terminantemente que eles contêm informaçб́es sobre o mundo objetivo. Posteriormente, deixa-se de ser tăo restritivo, porque não se tem tanta confiança na possibilidade de alcançar a esquiva, mas tão almejada certeza. Supóe-se, por isso, que as teorias são estruturas lógicas, instrumentos de cálculo, sem conteúdo empírico enquanto tais, que se conformam sempre ao modelo hipotético dedutivo. Não se pensa mais, em conseqüência, que a verdade - entendida como a adequação dos enunciados aos fatos - possa ser surpreendida, em momento algum, no âmbito do conhecimento cientffico. Acredita-se, no entanto, na possibilidade de dar crescente crédito às teorias por meio de validaçáo empirica sucessiva de suas conseqüéncias testáveis - e apenas por meio delas. Dito de outro modo, nessa versão do positivismo lógico, que sucede e se deriva da outra mencionada, ao invés de sustentar a atribuição de valor cognitivo na estrita verificaçăo, passa-se a apoiá-la no grau de confirmaçāo, ou seja, na progressiva prova frente aos fatos. Este critério envolve, aparentemente, uma exigência mais fraca. Aceita-se que é possível atribuir, probabilisticamente, maior valor de verdade ds proposiçőes quanto mais se mostrem resistentes às evidências contrárias. O grau de confirmação, ademais, é por isso tomado às vezes como um critério para a escolha de teorias alternativas (Caldwell, 1982, p.20-22). 
uma convenção para a sistematização das conexōes repetitivas entre os fenômenos. Como meio classificatório, deve estar constituída de modo coerente, preciso, exaustivo, obedecendo com rigor às regras da lógica formal. Enquanto tal, tem a função de abastecer o entendimento e de Ihe facilitar convenientemente o acesso à diversidade e iménsidão dos eventos possíveis, supostamente conhecidos. Como Marshall anteriormente já explicara - reivindica -, constitui-se em instrumento de raciocínio sistemático ou aparato de análise (engine of analysis) que orienta o entendimento na captura dos fatos.

Porém, teoria é também para Friedman "um corpo de hipóteses substantivas", ou seja, uma coleção de proposições com conteúdo factual, elaboradas para "abstrair características essenciais da realidade complexa" (1953, p.7) e obtidas por generalização das conexões repetitivas observadas entre os fenômenos. ${ }^{7}$ Nessa condição, no entanto, já não pode ser vista como um conjunto de tautologias; sua função agora é oferecer predições válidas e significativas sobre as ocorrências fenomênicas; válidas porque se espera que, sob certas condições, os eventos preditos venham realmente a ocorrer; significativas porque se referem à objetividade e podem ser verificadas por meio da observação $\mathrm{e}$ da experiência.

Só a evidência factual pode mostrar se $\rho$ sistema analítico possui efetivamente algum valor para as prospecções empíricas. Somente pelo poder de previsão podem as hipóteses ser avaliadas. Parece, de início, que é apenas no tribunal da experiência e no confronto com o objeto que a teoria científica vai a julgamento: "somente a evidência empírica pode mostrar se ela é "certa" ou "errada" ou, melhor dizendo, se pode ser tentativamente "aceita" como válida ou se deve ser "rejeitada" (1953, p.8). Se as previsões derivadas são contraditadas freqüentemente pelos fatos, então a hipótese é rejeitada; ao contrário, vem a ser aceita se resiste continuadamente a sucessivos testes. No tribunal da objetividade, se uma hipótese sobrevive numerosas vezes torna-se reconhecida, ele o diz, como uma formulação que foi confirmada pela experiência. $^{8} \mathrm{O}$ escrito de Friedman pode, de início, levar a pensar que as hipó-

7 Isto traz à tona um problema semelhante àquele posto pela distinçāo entre o positivo e o normativo no ámbito do pensamento. Para decidir se uma hipótese é substantiva é preciso avaliar o seu conteúdo de verdade. Trata -se de uma questáo que surge dentro de uma perspectiva indutivista do conhecimento (Boland, 1979, p.510).

8 Precisamente, Friedman diz que uma hipótese sucessivamente não refutada é vista, "de certo modo inexatamente, como uma hipótese que foi "confirmada" pela experiéncia" (1953, p.9). $O$ recurso de colocar palavras entre aspas é empregado largamente por esse autor no texto 
teses se transformam, pouco a pouco, em leis, ou seja, tornam-se mais verazes por meio de validações sucessivas de suas conseqüências frente aos fatos.

A sucessão de evidências não contraditórias, no entanto, como se sabe, apenas pode ser vista como confirmação progressiva de uma teoria se se admite, de antemão, que ela é provavelmente verdadeira. Somente sob essa suposição pode-se confiar na elevação do seu grau de veracidade, na medida mesmo em que se reiteram as evidências em seu favor. A escolha do grau de confirmação como critério de aceitação de hipóteses é circular, pois implica presumir o que se quer demonstrar, ou seja, que a teoria indiretamente testada já é verdadeira. Como esta circularidade cria dificuldades para decidir estritamente por meio de uma lógica da indução, costuma-se apoiar a crença na confirmação progressiva numa suposta convenção estabelecida pelos cientistas. ${ }^{9} \mathrm{Em}$ conseqüência, por mais que esses critérios requeiram o acúmulo de evidências objetivas em sua aplicação, o julgamento final dependerá, em última instância, de decisões que se afiguram como subjetivas.

De qualquer modo, vale a pena apreșentar a seguinte questão: aceitaria ele a indução como caminho da certeza? Poderia a separação entre o positivo e o normativo, segundo ele, ser sustentada mediante apelo à possibilidade de prova empírica progressiva? Logo se vê, no entanto, que se trata de um engano. Em seqüência, ele lembra que "a evidência empirica nunca pode "provar" uma hipótese" (1953, p.14), pois o mais que pode fazer é deixar de refutá-la (it can fail to disprove it). $\mathrm{Na}$ medida em que, entre outras coisas, menciona também que as hipóte-

examinado. Trata-se de um artiffcio para quase dizer, dizer com ambigüidade proposital, dizer sem se comprometer em demasia.

9

O confirmacionismo nasce da faléncia do verificacionismo. Na medida em que se deixa de acreditar na possibilidade de provar teorias mediante a observação e a experiência - porque se problematiza a indução como forma de justificação do conhecimento - torna-se inadmissfvel atribuir valor de verdade ao saber cientffico. Este sempre pemanecerá, agora, no fundo, como hipotético, ainda que as hipóteses possam e venham a ser consideradas mais ou menos razoáveis, segundo um critério que contém elementos subjetivos. Ao invés de crismar o suposto conhecimento como verdadeiro ou falso, passa-se a batizá-lo como melhor ou pior, válido ou inválido, confirmado ou rejeitado, etc. O próprio Carnap, que propós o grau de confirmação como critério de significância cognitiva e de cientificidade, declarou que, sob ele, "a aceitaçăo ou a rejeiçáo de uma sentença (sintética) sempre contém um componente convencional" (1985, p.173). É preciso mencionar aqui que se designa por convencionalismo a posiçăo que considera as teorias como meros arquivos de fatos. Porém, um problema de convenção sempre aparece quando falha a prova objetiva e se buscam critérios de decisáo para a justificação e a escolha de teorias que apelam, em última análise, para um almejado consenso (Boland, 1982, p.20-25). 
ses empiricamente resistentes são "tentativamente aceitas", pode-se inferir que, no fundo, ele está consciente da assimetria entre não rejeitar e aceitar, e que adota por força da lógica a alternativa mais fraca. Ora, isto implica, deve-se notar, já considerar que a verdade não pode ser afirmada no âmbito da ciência positiva e em recusar a lógica da indução. Em conseqüência, as hipóteses não podem ser mais ditas confirmadas no sentido da significância empirica.

Porém, ainda agora, parece que a experiência cumpre um papel fundamental no julgamento das teorias. Este não consiste, no entanto, em conduzir o cientista à descoberta do erro. Friedman não opta pelo falseacionismo, mas, ao contrário, procura um critério para preservar o acerto ou o que é considerado como tal. ${ }^{10}$ Por meio da experiência são selecionadas aquelas hipóteses que, em princípio, merecem sobreviver e continuar existindo nas prateleiras da ciência. Estas serão consideradas confirmadas quando mostram possuir capacidade de gerar predições bem-sucedidas. Porém, aqui também, surge a necessidade de recorrer a convenções admitidamente universais.

Para o economista, "a validade de uma hipótese... [no sentido da confirmação] não é por si mesma um critério suficiente para eleger hipóteses alternativas" (1953, p.9). Preocupa-o aqui a decisão sobre critérios de decisão para a escolha de teorias concorrentes. Ele quer mostrar, por exemplo, que dentre as teorias monetárias aquelas que se baseiam na teoria quantitativa da moeda devem ser as preferidas. Menciona que os fatos observados são necessariamente finitos, mas que as hipóteses adequadas para explicá-los, se pelo menos uma é possivel, são em princípio infinitas. Se uma decisão sobre teorias alternativas não pode mais confiar na prova objetiva, torna-se "até certo ponto arbitrária" $(1953$, p.10) e passa a requerer um balizamento de normas subjetivas. No tribunal friedmanita, o juiz olha os fatos, mas é de um modo subjetivo que dita a sentença final. $E$ ele tem os seus critérios últimos de cientificidade, os quais, inclusive, "desafiam por completo toda especificação objetiva" (1953, p.10). A melhor teoria, decide ele, vem a ser a mais simples e a mais frutifera. Será mais simples aquela que envolver menos informação prévia para realizar predições em certo campo fenomênico. Será mais frutífera aquela que encontrar aplicações mais amplas,

10 Segundo Boland, no ensaio de Friedman "testar" nunca significa "testar para rejeitar", mas sempre "testar para estabelecer a verdade" (testing for truth) da proposição diretamente confrontada com os fatos (1979, p.511). Existem autores que viram incompatibilidade entre a posição metodológica de Friedman e a lógica do teste (Bear e Orr, 1967, p.188-196). 
que puder originar maior número de pesquisas e da qual resultar prognoses mais acuradas. Se tais critérios são vistos como arbitrários, são aceitos porque são encarados como provenientes de um inconsútil "acordo geral" entre especialistas (1953, p.10).

Em decorrência desse resultado - necessário se torna concluir -, hipótese alguma pode ser dita ou vista, em qualquer estágio do conhecimento, como verdadeira ou provavelmente verdadeira. Nesse caso, em conseqüência, a disjunção entre o positivo e o normativo torna-se insustentável. Como garantir que uma hipótese ou teoria ora existente referese e se cinge ao que é? Friedman, porém, sobre isso nada explica e nem parece pensar na necessidade de fazê-lo. A distinção tradicional, uma reliquia do positivismo (Boland, 1982, p.15), aparece na introdução do escrito por uma razão estratégica. Cumpre ali o papel de fixar o mundo que está como um dado, algo que funciona como ordem automática e cujas "leis" precisa reconhecer, assimilar, conformando-se a elas. Isto permite postular a neutralidade: a ciência econômica positiva quer ser vista como independente dos interesses e fins que movem a politica econômica.

\section{REALISMO DA TEORIA}

A ciência positiva assim concebida, mesmo dependendo agora, em última instância, da preferência dos pesquisadores, continua almejando aprender o mundo objetivo. Os fatos são imprescindíveis no processo de construção de novas hipóteses e, como se viu, no procedimento de testar as já existentes. Não devem, no entanto, conforme ele, contribuir para o julgamento dos supostos teóricos enquanto tais. $O$ que deve interessar aos cientistas são apenas as implicações originadas das hipóteses e nunca se estas, em si mesmas, representam fielmente a realidade. Uma teoria não pode ser avaliada pelo seu grau de realismo. Não pode ser questionada no sentido da adequação dos seus supostos à realidade; mas apenas no que respeita à validade de suas prediçōes. Se se examina as realizações da ciência, descobrir-se-á, segundo Friedman, que "as hipóteses verdadeiramente importantes e significativas têm "supostos" que representam descritivamente a realidade de modo claramente inadequado e que, em geral, quanto mais significativa for a teoria, mais irrealista serão os seus "supostos". E ele aponta imediatamente a razão para esse sentenciar cortante. "Uma hipótese é importante se "explica" muito por meio de pouco, isto é, se abstrai os ele- 
mentos comuns e cruciais da massa de circunstâncias complexas e detalhadas que envolvem o fenômeno a ser explicado e permite predições válidas... Para ser importante, por conseguinte, uma hipótese deve ser descritivamente falsa em seus supostos" (1953, p.14).

Por irrealista, como a citação mostra, Friedman parece, de início, querer dizer apenas que as teorias são abstrações. Ele que dissera de inicio que as teorias são arquivos, dirá depois que um dos pressupostos básicos da ciência consiste em admitir que "a aparência é ilusória e que há um modo de olhar ou interpretar ou organizar a evidência que revelará fenômenos aparentemente desconexos como manifestações de uma estrutura mais fundamental e relativamente simples" (1953, p.33). Acentua, assim, de algum modo, que das construções teóricas não se pode exigir que exponham extensiva e compreensivamente qualquer circunscrição determinada do mundo objetivo. Se apenas isto tencionasse dizer, no entanto, a sua dissertação sobre a ausência de realismo nas formulações teóricas afigurar-se-ia simplesmente como trivial ( $\mathrm{Nagel}$, 1963, p.214).

Note-se aqui, a respeito disso, por um lado, ser duvidoso que os críticos tenham argüido a concorrência perfeita exclusivamente desse modo; esta seguramente Ihes parece não-razoável em outros sentidos além do meramente abstrato. E preciso admitir que eles questionaram a teoria dominante como explicação verossímil do funcionamento dos mercados na economia capitalista contemporânea. $O$ irrealismo subentendido pode significar, então, abstração não-essencial, simplificação arbitrária, compreensão inadequada, construção imaginária etc. Friedman claramente se esforça para reduzir o escopo do argumento dos críticos: assim eles parecem não saber bem o que é teoria. Já antes, porém, ele identificará teoria científica à teoria empírica e analítica.

Uma pergunta, pois, se insinua para aqueles que lêem o controvertido ensaio: por que se preocupa tanto Friedman em desqualificar a preocupação com o realismo na esfera da ciência econômica? Onde põe a linha de defesa das teorias que promove - e, assim, de suas implicaçōes para a política econômica - e que estão sendo atacadas?

Antes de mais nada, parece claro que para ele teoria alguma pode ser avaliada quanto à verdade ou à falsidade por introspecção. Ele não aceita, ademais, qualquer possibilidade de fundamentação da teoria em sentido ontológico, por meio da afirmação de sua correspondência ou fidelidade à natureza da coisa. Para Mill, que raciocinava sob uma ótica do psicologismo, o intento maximizador que atua e aparece na esfera 
do comportamento econômico é algo da essência humana. Este modo de pensar fora, porém, considerado essencialista por muitos partidários da ciência econômica positiva. As proposições científicas dessa espécie são agora vistas como convenções (1953, p.7), tipos ideais (1953, p.35), invenções (1953, p.43), podendo ser julgadas - não para averiguar a sua verdade - apenas por meio de suas conseqüências testáveis. Os supostos, em conseqüência, não possibilitam determinar a priori em que circunstâncias uma teoria vale (1953, p.19).

No dizer de Friedman, os supostos da boa teoria econômica são, portanto, irrealistas. Comentadores vários reclamaram da ausência no texto de uma clara e especifica conceituação do termo e especularam sobre as conseqüencias de the atribuir determinados significados. ${ }^{11} \mathrm{Se}-$ ria aceitável, para ele, uma hipótese patentemente inconsistente com os fatos? ́́ preciso ver que Friedman defende em seu escrito a tese do comportamento racional dos agentes capitalistas (maximização dos retornos esperados mediante igualação dos custos às receitas marginais) sem afirmar em nenhum lugar que ela é ou pode ser vista como realista, em algum sentido determinado. Ele se mostra sempre agnóstico quanto à possibilidade de questionar diretarnente a relação dos supostos teóricos com a realidade.

Ele não vê, por exemplo, como seria possível julgar tal suposto diretamente com base em evidências ocasionais ou mesmo apreensões sistemáticas dos fatos. Como aquilatar, propõe, a importância de uma visảo que mostrasse os empresários não tão egoístas, dinâmicos e racionais quanto a teoria marginalista os retrata? Ele duvida que haja qualquer base ou critério para um julgamento de discrepâncias dessa espécie (1953, p.32). Pensando apenas em termos quantitativos, não vê como encontrar um padrão de medida que permitisse avaliar a distância entre a teoria e a realidade. Também não admite sopesar o mesmo suposto pela sugestão de Weber segundo a qual, nas ciências sociais, somente se deve atribuir aos agentes motivos que tenham significado para eles próprios. Ainda que Friedman nada diga em específico sobre isso, critica as tentativas de levantar, por meio de questionários, as opiniōes de empresários a respeito dos fatores que afetam suas decisões econômicas. (Blaug, 1980, p.105). Tais estudos descritivos - ironiza equivalem a tentar encontrar as razões da longevidade perguntado às

11 Por exemplo, Rotwein (1959, p.555n), Nagel (1963, p.214-216), Melitz (1965, p.40-41), Blaug (1980, p.104). 
pessoas idosas porque viveram tanto tempo. ${ }^{12}$

De qualquer modo, ele sabe que os empresários não buscam conscientemente igualar o custo marginal à receita marginal, tal como a teoria postula. "Em um amplo conjunto de circunstâncias" - diz ele -, as firmas individuais se comportam como se (as if) estivessem procurando racionalmente maximizar os seus retornos esperados... e tivessem pleno conhecimento dos dados necessários ao sucesso do empreendimento" (1953, p.21). Em ambos os casos só importa saber se as fórmulas teoréticas funcionam (if they work) para prever os fenômenos que por meio delas estão sendo considerados.

\section{FICÇÃO CIENTÍFICA}

Em parágrafo algum, Friedman exprimiu melhor o seu ponto de vista do que naquele em que discute uma "explicação" para o modo como se arranjam as folhas na copa das árvores. Ele sugeriu, provocativamente, que seria possivel tratar esse fenômeno mediante a hipótese de que cada folha, deliberadamente, aí se arruma como se procurasse maximizar o recebimento de luz solar, levando em consideraçä́o a posição de suas vizinhas. Seria legitimo excluir essa hipótese do âmbito da ciência considerando-a falsa in limine, já que as folhas não são agentes racionais e ignoram as leis da física? A suposição enquanto explicação do comportamento das folhas parece duvidosa, mas a conclusão derivada, reclama èle, é claramente consistente com a experiência. Por isso, a sua resposta é clara: "nenhuma dessas contradições... é vitalmente relevante... [pois] a hipótese não estabelece que as folhas fazem tais coisas, mas somente que a sua densidade é a mesma como se as tivessem feito" (1953, p.20).

Com isso, ele interdita finalmente qualquer reflexão sobre o realismo das teorias. Já não se trata mais, como antes, de defender o caráter abstrato das formulaçóes científicas, mas em propugnar que o seu realismo não importa. Blaug, por isso, interpreta a argumentação de Friedman como uma tentativa radical de excluir o saber compreensivo do âmbito da ciência econômica (1980, p.105). A adesão, antes mencionada, à tese de que as teorias são representações abstratas da esfera

12 Note-se: esse não é um fenómeno que possa ser explicado exclusiva ou principalmente por meio de uma hipótese sobre a conduta, em especial, sobre a conduta guiada conscientemente. 
fenomênica ou generalizaçōes de certas conexōes entre fatos cumpriu, no devido momento, o seu papel: ajudou-o a tentar aniquilar os adversários da teoria neoclássica.

Friedman, de início, descura da verdade da teoria, depois, ele descura também de sua falsidade. A hipótese teórica pode ser falsa, desde que se possa retirar dela predições verdadeiras. Uma teoria pode não se referir ao que é, desde que as suas conclusões o façam. Estas, ao contrário das hipóteses fundantes e dos teoremas derivados, podem e devem ser descritivamente verdadeiras. Isto já não é convencionalismo, mas instrumentalismo, ${ }^{13}$ uma posição metodológica que considera as teorias apenas como ferramentas para a previsão - em si mesmas, portanto, nem verdadeiras nem falsas. Compreendendo as teorias como formulaçōes simbólicas destituidas de autêntico conteúdo empírico, havendo concluído que as hipóteses não podem ser verificadas ou mesmo, finalmente, comprovadas, pensa, no entanto, que os enunciados particulares delas derivados por implicação devem ser verificáveis ou comprováveis de algum modo. Isto recoloca, agora ao nível das predições, o problema da certeza.

Viu-se anteriormente que, na escolha de teorias, a aplicação dos critérios convencionais de simplicidade e de fertilidade (fruitfulness) para a escolha de teorias somente pode ocorrer se as teorias concorrentes se apresentam como igualmente contirmadas. Somente as hipóteses cujas implicaçōes se mostram verdadeiras frente aos fatos podem participar de uma eleição final, segundo aqueles dois crivos complementares. Corno reforça o próprio autor. "o teste decisivo é se a hipótese funciona [no sentido do poder de previsão] em relação ao fenômeno que intenta explicar" (1953, p.30). Porém, como obter essa certeza?

O caminho do economista que adere ao programa da ciência positiva não é, no entanto, reto e fácil, nesse aspecto crucial, onde a sugestão metodológica de Friedman faz sentido ou entra em colapso. É preci-

13 As duas posições nascem da dificuldade associada à possibilidade de justificar teorias, ou seja, de prová-las como verdadeiras quanto ao conteúdo objetivo. Enquanto o convencionalismo contenta-se com o problema formal da escolha de leorias, ou seja, dos critérios de docisão a respeito do melhor sistema de arquivo dos fatos, o instrumentalismo ambiciona ultrapassar tal viés subjetivista, preocupando-se de novo com a captação das regularidades do mundo objetivo. Como as teorias, corn a descrença na indução, náo podem em si mesmas ser ditas verdadeiras - apenas eventualmente falsas -, sáo vistas nesta última posiçáo apenas como algo que vale por seus fins e utilidade, isto é, como instrumentos de prediçáo. A questão que aqui se póe é se o instrumentalismo pode se justificar a si mesmo; caso contrário, recai-se necessariamente num problema de convenção. 
so procurar em geral hipóteses que funcionem. Subsistem, no entanto, dificuldades de monta no caminho daqueles que desejam encontrá-las. Não há possibilidade - desafortunadamente, segundo ele - de realizar experimentos controlados nas ciências sociais para verificar predições. Trata-se, por certo, de uma desvantagem, mas não é este para ele o principal problema. O curso dos acontecimentos fornece abundante $\mathrm{e}$ variada experiência para todos aqueles que querem testar. "Mas tal espécie de evidência é de muito mais difícil interpretação" (1953, p.10). O garimpo dos fatos empíricos disponíveis - diz - é muitas vezes árduo e os resultados obtidos - completa - mostram-se freqüentemente complexos, indiretos e incompletos. "Isto torna a extirpação das hipóteses malsucedidas lenta e difícil" (1953, p.11). Como resultado, o consenso e a convicção parecem agora alvos difíceis de alcançar. ${ }^{14}$ Tudo isso é amplamente sabido. A questão importante vem a ser outra: há em Economia hipóteses firmemente confirmadas no sentido do poder de previsão?

A confirmação de teorias na ciência social é tomada, assim, como problemática em geral, a hipótese de maximização de retornos é vista, no entanto, como amplamente corroborada. Trata-se de um instrumento de previsão - acredita - que sobreviveu e tem sobrevivido a sucessivos e numerosos testes. Os argumentos que aduz em favor dessa opinião são no mínimo insólitos. Toma, primeiro, o processo que a concorrência capitalista submete as firmas individuais como uma prova de que a teoria funciona. Esta resume, segundo ele, as condições segundo as quais essas firmas teriam de obedecer para subsistir no mercado, concluindo daí que o processo de "seleção natural" ajuda a confirmar a hipótese. "A menos que o comportamento do empresário, de um modo ou de outro, seja aproximadamente consistente com a hipótese de maximização de retornos, parece improvável que ele permaneça por muito tempo no negócio" (1953, p.22). Desse modo, no entanto, a teoria não é testada. A evidência empírica aqui não é empregada para julgar a hipótese, mas,

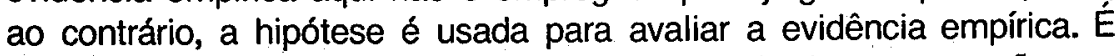
preciso ver que Friedman assume a maximização de retornos, não verdadeiramente como hipótese, mas como quinta-essência do comportamento racional. Isto é certamente possivel, mas exige uma justificação

14 Friedman condena àqueles especialistas que se deixam seduzir pela economia matemática: "um dos efeitos da dificuldade de testar hipóteses substantivas" - diz ele - "tem sido provocar um recolhimento dentro da análise puramente formal ou tautológica" (1953, p.11). Mas também foi criticado por eles (Koopmans, 1957, p.129-30). 
de outra espécie - obviamente uma justificação não empírica.

Além desse argumento, Friedman lança mão de um outro mais forte. Para demonstrar que tal suposição teórica encontra-se bem-confirmada, reivindica que se olhe o amplo apoio das aplicações bem-sucedidas da teoria neoclássica. Apresentam-se como incontáveis as vezes diz ele - que as implicações da hipótese de maximização de retornos deixaram de ser contraditadas. A evidência favorável existe - explica -, ainda que seja extremamente difícil de documentar, pois se encontra espalhada em inúmeros artigos, monografias, relatórios etc. Isto parece mais certo do que errado, principalmente porque os economistas nem sempre costumam relatar o insucesso. No entanto, se se trata apenas do poder de predição, uma afirmação em sentido contrário - deve-se convir - seria igualmente correta: devem ter sido inúmeras as vezes em que as prognoses feitas com base na teoria ortodoxa da firma não se confirmaram. De qualquer modo - é preciso notar -, Friedman formula aqui um argumento sedutor. A evidência que vindica para o suposto de maximização é da mesma natureza, no entanto, da evidência difusa que usualmente se reclama para as realizações da quiromancia e da astrologia.

Friedman, no inicio de seu escrito, postula que a Economia é conhecimento sobre o que é, ciência positiva. ${ }^{15}$ Descobre-se, depois, que ela não é sequer um saber explicativo, mas apenas um conjunto de instrumentos de predição, os quais devem mostrar o seu valor no desempenho efetivo da sua função instrumental. Como sabê-lo, porém? Nem sempre são encontradas nas ciências sociais - escreve em certo momento - as condições adequadas para realizar testes decisivos. Porém, mesmo quando um tal teste pode ser feito, a formação do cientista não é irrelevante para os julgamentos a que chega. Nunca há certeza na ciência e o peso da evidência a favor ou contra uma hipótese nunca pode ser avaliada de um modo completamente "objetivo" (1953, p.30). Isto ele também diz, assim se protege de uma objeção óbvia.

Em suma, o texto de Friedman é uma feira de idéias metodológicas, ai reunidas com a finalidade de anular sinuosamente o papel da compreensão e da reflexão em Economia. O seu inequívoco sucesso é já a denúncia de uma época em que o comércio de idéias, sob a aparência sisuda da economia positiva, é bem apreciado no mercado das

15 Uma crf́tica à idéia da Economia como ciência só positiva encontra-se em Prado (1989, p.135-151). 
doutrinas econômicas. Eis que se trata justamente de uma época em que a questão da verdade foi esmagada pelo problema do sucesso. Contudo, nada denuncia melhor. Friedman do que o seu silêncio estratégico diante das várias críticas feitas ao seu artigo: ele nunca respondeu a nenhuma delas...

\section{BIBLIOGRAFIA}

BEAR, D.V.T. \& ORR, D. Logic and Expediency in Economic Theorizing. The Journal of Political Economy, v.75, Apr. 1967, p.108-96.

BLAUG, M. The Methodology of Economics, or how Economists Explain. Cambridge, Cambridge University Press, 1980.

BOLAND, L., Friedman's Methodology vs. Conventional Empiricism. A Reply to Rotwein. Journal of Economic Literature, v.18, Dec. 1980, n.1555-7.

A Critique of Friedman's Critics. Journal of Economic Literature, v.17, June 1979, p.503-22.

CALDWELL, B.J. Beyond Positivism: Economic Methodology in Twentieth Century. Londres, George Allen and Unwin, 1982.

COMTE, A. Comte - Sociologia. São Paulo, Ática, 1983. (Col. Grandes Cientistas Sociais, org. por E. Moraes Filho).

FRIEDMAN, Milton. The Methodology of Positive Economics. In: Essays on Positive Economics. Chicago, The University of Chicago Press, 1953, p.3-43.

KEYNES, J.N. The Scope and Method of Political Economy. Londres, Macmillan, 1917.

KLAPPHOLZ, K, \& AGASSI, J. Methodological Prescriptions in Economics. Economica, v.26, 1959, p.60-74.

KOOPMANS, T.C. Three Essays on the State of Economic Science. New York, McGraw-Hill, 1957.

MCCLOSKEY, D.N. The Rhetoric of Economics. Madison, The University of Wisconsin Press, 1985.

MACHLUP, F. Methodology of Economics and Other Social Sciences. New York, Academic Press, 1978.

MELITZ, J. Friedman and Machlup on the Significance of Testing Economic Assumptions. The Journal of Political Economy, v.78, n.1, Feb. 1965, p.37-60.

NAGEL, E., Assumptions in Economic Theory. American Economic Review, 1963. 
PRADO, Eleutério F.S. Um Estudo Sobre a Compreensão da Economia Como Ciência. São Paulo, IPE/USP, 1989. Tese (liv. doc. econ.), USP.

A Meça da Economia Positiva, o último Peregrino? In: ENCONTRO NACIONAL DE ECONOMIA, 17, Fortaleza, 1989, Anais..., Brasilia, ANPEC, 1989, v.1, p.135-51.

ROTWEIN, E. On "The Methodology of Positive Economics", Quarterly Journal of Economics, v.73, 1959, p.554-75.

SAMUELSON, P.A. Problems of Methodology -- Discussion. American Economic Review, v.53, May 1963, p.231-6.

SCHUMPETER, J.A. History of Economic analysis. New York, Oxford University Press, 1954.

STANLEY, T.D. Positive Economics and its Instrumental Defense. Economica, v.52, Aug. 1985, p.305-19.

\section{ABSTRACT \\ A KNOWLEDGE THAT DOES NOT KNOW: INSTRUMENT FOR PREDICTION}

This article reexamines the well-known and controversial Friedmans's methodological proposal. It intends to show, through an internal critique, that the text is full of contradictions. It is moreover suggested that the proposal was made within an argument of protecting neoclassical theory from criticism. The article also tries to make evident that Friedman, in this attempt, violates the implicit ethics of the academic discourse, which has the search for truth, normative correctness and sincerity as internal suppositions. 